\title{
Mahboub Saffari* \\ Response surface methodological approach for optimizing the removal of cadmium from aqueous solutions using pistachio residues biochar supported/non-supported by nanoscalezero-valent iron
}

https://doi.org/10.1515/mgmc-2018-0011

Received March 11, 2018; accepted October 16, 2018; previously published online November 15, 2018

Abstract: A three-level Box-Behnken model (BBM) under response surface methodology (RSM) was used to optimize the removal of cadmium $(\mathrm{Cd})$ ion by pistachio residues biochar (PRB) and PRB supported by nanoscale zero-valent iron (PRB-nZVI) from aqueous solutions. Optimization experiments were carried out by evaluation of the effect of four variables (initial Cd concentration, initial solution $\mathrm{pH}$, adsorbent dosage, and contact time) at three levels (high, medium, and low), and one category contained two variables (PRB and PRB-nZVI). For this purpose, a total of 58 experimental runs were set and the experimental data were fitted to the empirical second-order polynomial model of a suitable degree. The physical and chemical structure results of the adsorbents confirmed the formation of nZVI (with diameters $\sim 35 \mathrm{~nm}$ ) on the PRB surface. The results showed that the new composite of biochar (PRB-nZVI) exhibited higher Cd removal efficiency compared with PRB from aqueous solutions. The existence of functional groups and nZVI on the surface of PRB-nZVI could be better than PRB for Cd removal in aqueous solutions by the processes of sorption, precipitation, and co-precipitation. Numerical optimization revealed that the optimum removal $(96.58 \%)$ ) was obtained at an initial Cd concentration of $25.99 \mathrm{mg} \mathrm{L}^{-1}$ (pH 6.58), adsorbent dose (PRB-nZVI) of $0.55 \mathrm{~g} \mathrm{~L}^{-1}$, and contact time of $34.11 \mathrm{~min}$, with desirability of 1 . Based on the results, it is recommended that PRB-nZVI can be effectively used for the removal of $\mathrm{Cd}$ from a contaminated aqueous solution with varying chemical and physical conditions.

Keywords: biochar; cadmium; nanoscale zero-valent iron; removal; response surface methodology.

\footnotetext{
*Corresponding author: Mahboub Saffari, Environment Department, Institute of Science and High Technology and Environmental Sciences, Graduate University of Advanced Technology, Kerman, Iran, e-mail: Mahboobsaffari@gmail.com
}

\section{Introduction}

Increasing industrial and human activities have led to the release of high amounts of heavy metals (HMs) to the environment, which have caused several problems in today's societies because of their adverse effects on human health (Tchounwou et al., 2012). Cadmium (Cd) is known as one of the HMs that the US Environmental Protection Agency has classified as a group B1 carcinogen (Wang et al., 2010). Wastewater from the industries of electroplating, melting, color pigments, batteries, and chemical fertilizers are the main sources of Cd pollution in the environment (Satarug et al., 2011). The maximum allowable concentrations of $\mathrm{Cd}$ in refined industrial wastewater, which can be discharged to the receiving water and drinking water, are 0.25 and $0.005 \mathrm{mg} \mathrm{L}^{-1}$, respectively (Li et al., 2003). Several methods have been investigated for HMs removal from aqueous environments, including chemical precipitation, ion exchange, reverse osmosis, membrane processes, evaporation, and adsorption (Fu and Wang, 2011). Because of their high efficiency and easy application, surface adsorption methods are known as the best methods that have been widely used to remove pollutants (Demirbas, 2008). Different types of clay, zeolite, biopolymer, microorganisms, coal fly ash, sewage sludge, and activated carbon are the conventional adsorbents that have been used for $\mathrm{Cd}$ removal (Rao et al., 2010). Scientists have started to identify low-cost, suitable, efficient, and easily available types of adsorbents, particularly from waste, to remove pollutants from environments (Ngah and Hanafiah, 2008). The environmental problems caused by agricultural waste can be reduced by reusing the waste through pyrolysis into biochar (Qambrani et al., 2017). Biochar is known as a carbon-rich material that is produced under oxygen-limited environment by thermochemical treatment, which can be used as an adsorbent for organic and inorganic contaminants (Ahmad et al., 2014). Pollutant removal efficiency of each biochar depends on their physical and chemical properties, which are considerably affected by the sources of biomass, time and temperature of pyrolysis, and pyrolysis conditions (Ahmad et al., 2014; Tan et al., 2015). Some researchers claim that application of pristine biochar in 
highly polluted aqueous solutions could not adsorb pollutants more efficiently (Yao et al., 2013); so to overcome this problem, the production of engineered biochars with novel structures and surface properties was recommended (Zhang et al., 2013; Gan et al., 2015). Biochar-based nanocomposites are one of the engineered biochars that have been used by many researchers (Zhang et al., 2012, 2013; Wang et al., 2013) to remove aqueous contaminants. Waste management, pollutant removal, carbon sequestration, and energy production are four integrated goals obtained from the synthesis of biochar-based nanomaterials (Sohi, 2012; Tan et al., 2015, 2016). Nanoscale zero-valent iron (nZVI) has been used in several researches, as an adsorbent, for the removal various HMs such as $\mathrm{Cd}^{2+}$ (Boparai et al., 2013), $\mathrm{As}^{5+}$ (Rahmani et al., 2011), $\mathrm{Cr}^{6+}$ (Alidokht et al., 2011), and $\mathrm{Pb}^{2+}$ (Esfahani et al., 2014) in aqueous solutions. The agglomeration of nZVI particles limits the migration distance, which inhibits their usefulness (Phenrat et al., 2008). Thus, it seems that nZVI particles that are supported on solid materials (Quan et al., 2014b) could increase the stability of nZVI. In addition, separation of pristine biochar, as nonmagnetic sorbents, from aqueous solutions is very difficult and costly. Therefore, the production of magnetic biochar can be used to facilitate better separation and recovery problems of biochar particles after the treatment process (Zhang et al., 2013). Knowing the main factors that affect removal of HMs from aqueous solutions can help researchers to achieve optimum results. However, to achieve these optimal points, a lot of testing and time is required. To overcome these problems, the response surface methodology (RSM), as an alternative method with a minimum number of tests, can be a suitable replacement. The RSM is a set of mathematical methods that determine the relationship between one or more response variables with several independent variables, which can be used for experiment designation and simultaneous optimization of several variables. The use of biochar zero-valent iron as an adsorbent for the removal of HMs has not been extensively investigated; and only its effects on organic pollutants including acid orange 7 (Quan et al., 2014a), methylene blue (Pi et al., 2015), methyl orange (Han et al., 2015), pentachlorophenol (Devi and Saroha, 2015), tar (Kastner et al., 2015), and trichloroethylene (Yan et al., 2015) were assessed. Therefore, the objective of this study was to evaluate the ability of pistachio residues biochar (PRB) to remove $\mathrm{Cd}$ in aqueous solutions compared with that of PRB supported by nanoscale zero-valent iron (PRB-nZVI), in different experiment conditions including $\mathrm{Cd}$ concentration, solution $\mathrm{pH}$, contact time, and dosage of adsorbents, using Box-Behnken model (BBM) under RSM.

\section{Results and discussion}

\section{Characterization of PRB and PRB-nZVI}

The European Biochar Certificate (2012) has introduced biochar, a material that has a minimum of $50.0 \%$ carbon (C) and maximum of $0.7 \mathrm{H} / \mathrm{C}$. Prepared PRB in this study contained $66.5 \% \mathrm{C}$ and its $\mathrm{H} / \mathrm{C}$ ratio was 0.06 (Table 1). According to the results of the PRB analysis (Table 1), removal of unstable compounds compared to the pistachio residues (PR) caused PRB to have higher percentages of $C$ (due to carbonization during pyrolysis) but much lower hydrogen (loss of H-containing functional groups), nitrogen $(\mathrm{N})$, and sulfur (S) contents. Pyrolysis temperature led to increased $\mathrm{pH}$ (from 6.8 to 10.4) and electrical conductivity (EC) (from 3.4 to $7.7 \mathrm{dS} \mathrm{m}^{-1}$ ). The increase in $\mathrm{pH}$ of PRB compared with that of PR could be due to the higher basic functional groups, basic salts separation from organic compounds, and lower acidic functional groups (Mukherjee et al., 2011). In contrast, the lower $\mathrm{pH}$ of PRB-nZVI (8.1) compared with that of PRB might be due to several washes with sulfuric acid and distilled water, which might have washed the soluble basic cations out. Elemental composition of the PRB-nZVI showed higher percentage of $\mathrm{H}$ and lower percentage of $\mathrm{C}$ and $\mathrm{N}$ compared with the PRB. Increased H contents in PRB-nZVI could be due to the production of hydrogen gas during the production of PRB-nZVI.

The Fourier transform infrared spectroscopy (FTIR) spectra band of of PR, PBR, and PBR-nZVI is shown in Figure 1. As can be seen, the pyrolysis producer (PRB compared with PR) decreased the intensity of the bands assigned to the hydroxyl group stretching (3500-3200 $\mathrm{cm}^{-1}$ ) and the aliphatic C-H deforming vibration (2980-2820 $\mathrm{cm}^{-1}$ ), which showed that demethoxylation, dehydration, and demethylation of lignin have occurred (Sharma et al., 2004; Kloss et al., 2012). Several researches showed that enhancing dihydroxylation and loss of hydroxyl group and aliphatic groups in biochars (prepared above $400^{\circ} \mathrm{C}$ ) caused an increase in their pore formation because of a concurrent development of fusedring structures (Kloss et al., 2012). The band at $1615 \mathrm{~cm}^{-1}$

Table 1: Selected chemical composition of PR, PBR, and PBR-nZVI.

\begin{tabular}{|c|c|c|c|c|c|c|c|}
\hline Samples & $\mathrm{pH}$ & $\mathrm{EC}\left(\mathrm{dS} \mathrm{m}^{-1}\right)$ & n (\%) & $C(\%)^{a}$ & $\mathbf{S}(\%)^{\mathrm{a}}$ & H (\%) & $\mathrm{H} / \mathrm{C}$ \\
\hline PR & 6.8 & 3.4 & 4.45 & 57.25 & 0.58 & 5.83 & 0.10 \\
\hline PRB & 10.4 & 7.7 & 3.46 & 66.55 & 0.49 & 4.26 & 0.06 \\
\hline PRB-nZVI & 8.1 & 3.8 & 0.8 & 33.6 & 0.53 & 5.1 & 0.15 \\
\hline
\end{tabular}

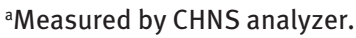




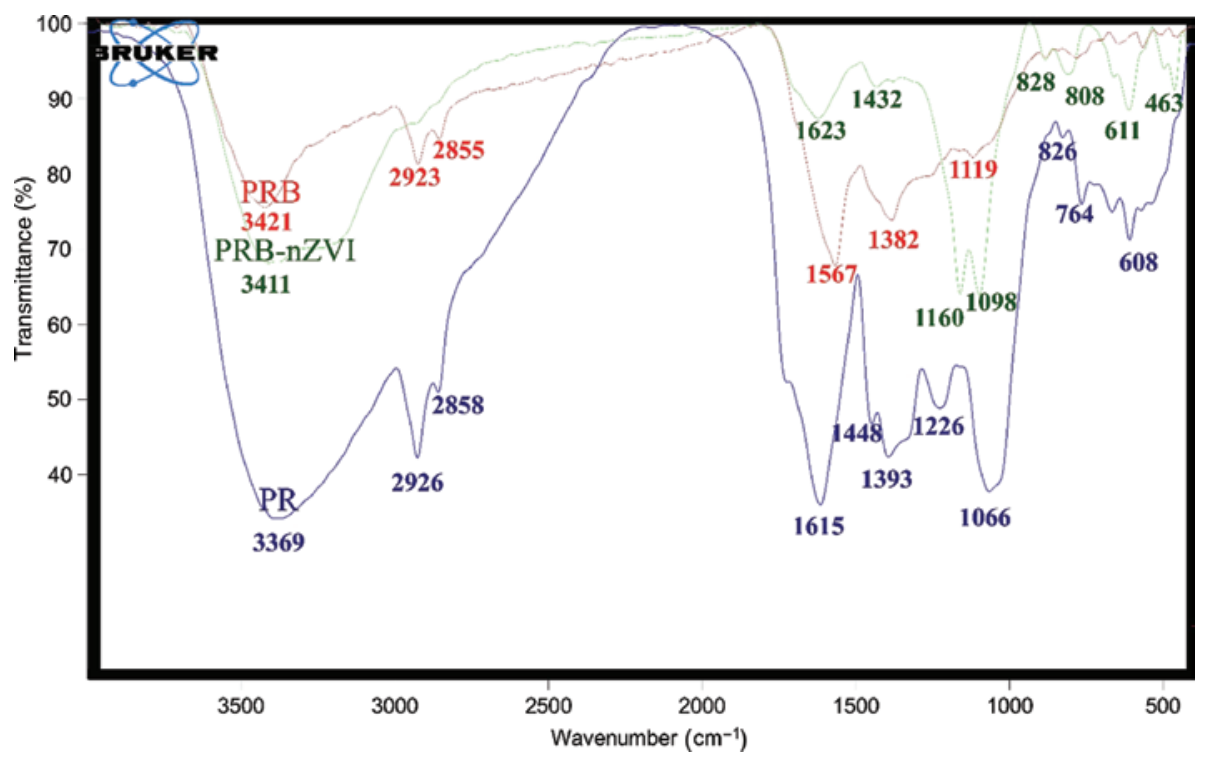

Figure 1: FTIR spectra of PR, PRB, and PRB-nZVI.

for PR, which disappeared for PRB (due to volatilization of nitrogen forms), is assigned C-N. In contrast, the band at $1567 \mathrm{~cm}^{-1}$ for PRB is due to the presence of aromatic $\mathrm{C}=\mathrm{O}$ vibration in lignin, implying the presence of residual lignin after decomposition. The smaller pick shown at the region $1400-1450 \mathrm{~cm}^{-1}$ in PR is due to $\mathrm{C} 6$ ring modes, which disappears in PRB. The band at $1066 \mathrm{~cm}^{-1}(1000-$ $1200 \mathrm{~cm}^{-1}$ ) for PR tended to decrease with pyrolysis producer, which is assigned to $\mathrm{C}-\mathrm{O}$ stretching vibration from carbohydrates. The results from the FTIR analysis of PRB showed the functional groups such as carboxylic bonds and aromatic $\mathrm{C}=\mathrm{O}$ ring stretching (likely $-\mathrm{COOH}$ ) were increased compared with those of PR. Moreover, the FTIR spectra band of PRB-nZVI was also scanned (Figure 1). The bands at 2923, 2855, 1567, and $1382 \mathrm{~cm}^{-1}$ for PRB, which disappeared in PRB-nZVI, indicate that $\mathrm{Fe}^{3+} / \mathrm{Fe}^{0}$ interacted with the surface's functional groups (Zhu et al., 2017). In addition, disappearing of bands around $2900 \mathrm{~cm}^{-1}$ in PR and PRB compared with PRB-nZVI might be due to the removal of polar functional groups during co-precipitation of $\mathrm{Fe}^{0}$. The band at $460 \mathrm{~cm}^{-1}$ PRB-nZVI was assigned to Fe-O. Furthermore, the band at $1119 \mathrm{~cm}^{-1}$ for PRB shifted for PRB-nZVI to 1160 and $1098 \mathrm{~cm}^{-1}$. In general, the results of the FTIR analysis indicate that the pyrolysis temperature increased the aromatic properties in biochar, and it is expected that the changing surface properties of biochar might affect the adsorption behavior of $\mathrm{Cd}$.

To confirm the successful synthesis of PRB-nZVI, the analysis of XRD was done (Figure 2). As can be seen in Figure 2, a sharp peak at $2 \theta=44.7^{\circ}$ in the XRD pattern of the

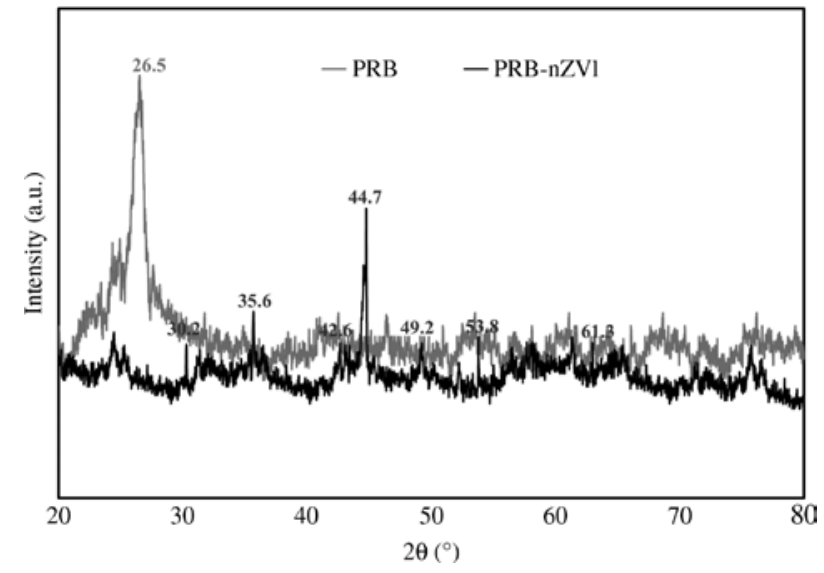

Figure 2: XRD patterns of a PRB and PRB-nZVI.

PRB-nZVI proved that $\mathrm{Fe}^{0}$ was formed on the surfaces of biochar. A similar result was observed by Peng et al. (2017) and Ahmad et al. (2018) who found a peak at $2 \theta=44^{\circ}$ in nZVI/biochar composite. The peaks at $2 \theta=20-30^{\circ}\left(26.5^{\circ}\right)$ in PRB was due to the amorphous carbonaceous structure, which disappeared in PRB-nZVI. In addition, the weak and moderate peaks at $30.2^{\circ}, 35.6^{\circ}, 53.8^{\circ}$, and $61.3^{\circ}$ were observed in PRB-nZVI, which were signals of iron oxide (magnetite). Similar results were obtained by $\mathrm{Zhu}$ et al. (2017) and Jiang et al. (2011) who explained that the thin surface of the $\mathrm{Fe}^{0}$ particles may be oxidized under the drying and fabricating process. In addition, the presence of the functional oxygen-containing groups on the surface of biochar (such as carboxyl, hydroxyl, and aliphatic ethers) might form surface oxygen-containing complexes 
with Fe ions through stabilization absorption configurations (Cui et al., 2016; Yang et al., 2016). The field emission scanning electron microscope (TESCAN FE-SEM MIRA3) was also used to investigate the morphological characteristics of PRB and PRB-nZVI (Figure 3). The result of the FE-SEM analysis showed that nZVI was consistently circulated across the entire PRB surface (tube-like structures). In addition, it can be observed that the ZVI particles are in the form of nanospheres, having diameters approximately $35 \mathrm{~nm}$ (Figure 3D). Generally, the results from the XRD and FE-SEM analyses indicated that the nZVI was deposited on the biochar.

\section{Cd removal efficiency, experimental design, and fitting of polynomial model}

The results of Cd removal percentage by PRB and PRBnZVI under different conditions are shown in Table 2. The affinity of Cd was considerably different for PRB and PRBnZVI. As a result, PRB-nZVI was more effective than PRB in removing $\mathrm{Cd}$ from an aqueous solution. The removal of Cd reached $26.12 \%-80.44 \%$ (on average $38.67 \%$ ) and $29.8 \%-95.48 \%$ (on average $67.96 \%$ ) after the addition of PRB and PRB-nZVI, respectively. In an aqueous solution, Fe reacts with water and oxygen and forms a layer of
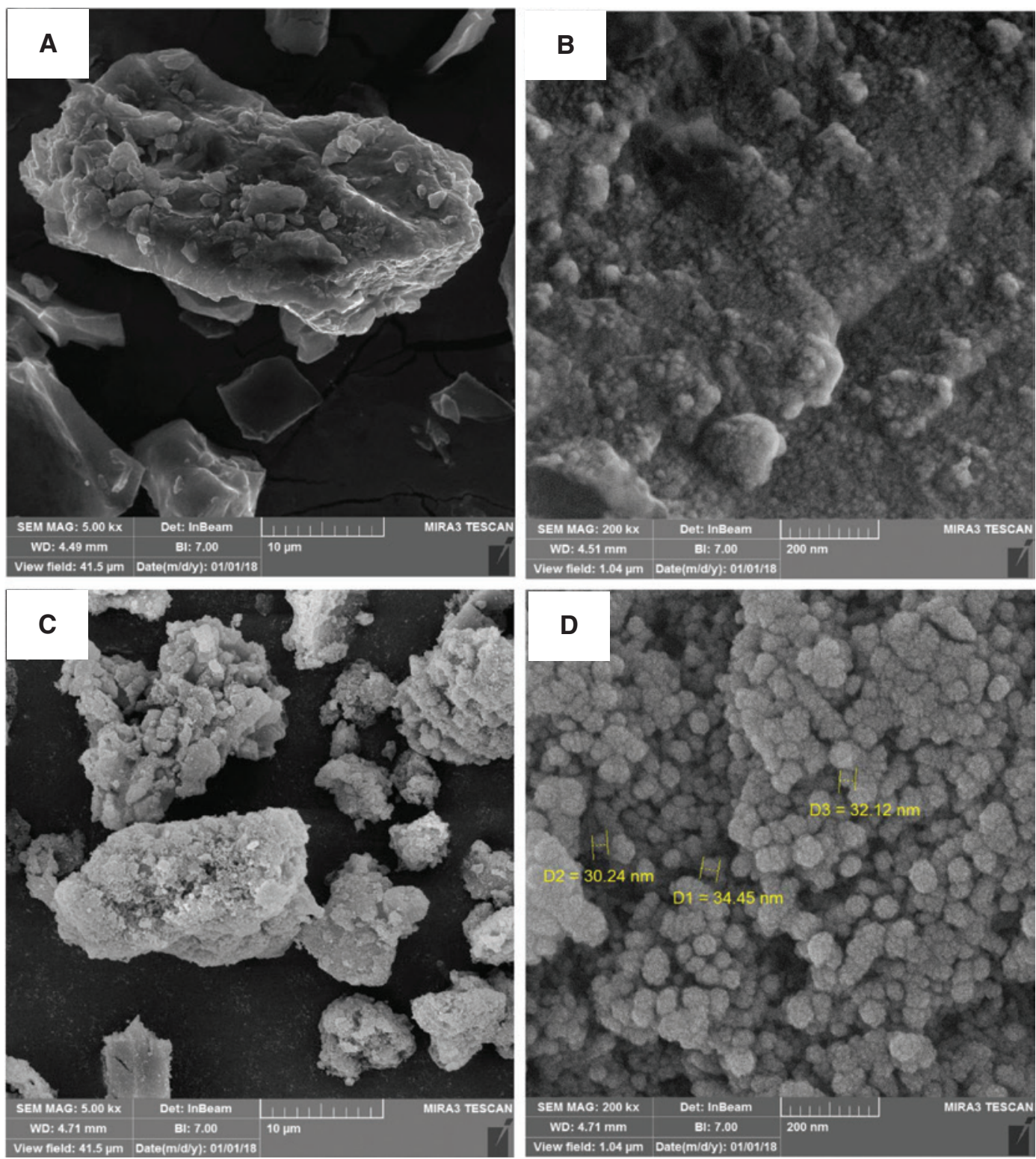

Figure 3: FE-SEM images of pristine biochar ( $A$ and $B)$ and engineered biochar $(C$ and $D)$ at various magnifications. FE-SEM images of PRB (A, scale $10 \mu \mathrm{m}$; B, scale $200 \mathrm{~nm}$ ) and PRB-nZVI (C, scale $10 \mu \mathrm{m}$; D, scale $200 \mathrm{~nm}$ ). 
Table 2: Experimental design based on BBM used in this study.

\begin{tabular}{|c|c|c|c|c|c|c|c|c|c|c|c|c|c|}
\hline Run order & $\mathbf{x} 1$ & $\mathrm{X} 2$ & X3 & $X 4$ & $\times 5$ & Cd removal (\%) & Run order & $\mathrm{X} 1$ & $\mathrm{X} 2$ & X3 & $X 4$ & $\times 5$ & Cd removal (\%) \\
\hline 1 & 50 & 5 & 1.25 & 40 & PRB & 37.63 & 30 & 50 & 7 & 1.25 & 60 & PRB-nZVI & 86.50 \\
\hline 2 & 50 & 5 & 2 & 60 & PRB & 31.28 & 31 & 75 & 5 & 2 & 40 & PRB & 30.33 \\
\hline 3 & 50 & 5 & 0.5 & 20 & PRB & 36.86 & 32 & 50 & 7 & 1.25 & 20 & PRB & 43.76 \\
\hline 4 & 25 & 5 & 2 & 40 & PRB & 32.44 & 33 & 50 & 7 & 0.5 & 40 & PRB & 54.50 \\
\hline 5 & 75 & 5 & 1.25 & 20 & PRB & 29.69 & 34 & 75 & 5 & 1.25 & 60 & PRB & 33.12 \\
\hline 6 & 50 & 5 & 1.25 & 40 & PRB & 40.10 & 35 & 50 & 7 & 1.25 & 20 & PRB-nZVI & 81.94 \\
\hline 7 & 50 & 7 & 2 & 40 & PRB & 40.48 & 36 & 25 & 5 & 1.25 & 20 & PRB & 29.32 \\
\hline 8 & 50 & 5 & 1.25 & 40 & PRB-nZVI & 84.38 & 37 & 50 & 5 & 2 & 20 & PRB & 80.44 \\
\hline 9 & 50 & 7 & 0.5 & 40 & PRB-nZVI & 78.63 & 38 & 25 & 5 & 0.5 & 40 & PRB-nZVI & 82.32 \\
\hline 10 & 50 & 5 & 0.5 & 60 & PRB-nZVI & 73.74 & 39 & 50 & 3 & 1.25 & 20 & PRB & 29.86 \\
\hline 11 & 50 & 7 & 1.25 & 60 & PRB & 40.64 & 40 & 75 & 7 & 1.25 & 40 & PRB & 35.00 \\
\hline 12 & 50 & 5 & 1.25 & 40 & PRB-nZVI & 35.14 & 41 & 50 & 7 & 2 & 40 & PRB-nZVI & 83.48 \\
\hline 13 & 50 & 3 & 0.5 & 40 & PRB-nZVI & 34.60 & 42 & 50 & 5 & 1.25 & 40 & PRB & 31.72 \\
\hline 14 & 50 & 3 & 1.25 & 20 & PRB-nZVI & 43.32 & 43 & 50 & 5 & 1.25 & 40 & PRB-nZVI & 82.36 \\
\hline 15 & 25 & 3 & 1.25 & 40 & PRB-nZVI & 61.56 & 44 & 50 & 3 & 2 & 40 & PRB-nZVI & 72.20 \\
\hline 16 & 25 & 5 & 1.25 & 20 & PRB-nZVI & 80.28 & 45 & 25 & 7 & 1.25 & 40 & PRB-nZVI & 95.48 \\
\hline 17 & 75 & 5 & 2 & 40 & PRB-nZVI & 81.63 & 46 & 50 & 3 & 0.5 & 40 & PRB & 33.62 \\
\hline 18 & 75 & 5 & 1.25 & 20 & PRB-nZVI & 75.93 & 47 & 25 & 5 & 0.5 & 40 & PRB & 53.48 \\
\hline 19 & 50 & 5 & 1.25 & 40 & PRB & 33.58 & 48 & 25 & 7 & 1.25 & 40 & PRB & 71.04 \\
\hline 20 & 50 & 5 & 2 & 60 & PRB-nZVI & 83.64 & 49 & 75 & 7 & 1.25 & 40 & PRB-nZVI & 79.08 \\
\hline 21 & 25 & 3 & 1.25 & 40 & PRB & 26.12 & 50 & 50 & 5 & 2 & 20 & PRB-nZVI & 29.86 \\
\hline 22 & 75 & 5 & 1.25 & 60 & PRB-nZVI & 84.19 & 51 & 50 & 5 & 1.25 & 40 & PRB-nZVI & 37.22 \\
\hline 23 & 50 & 5 & 0.5 & 20 & PRB-nZVI & 67.40 & 52 & 50 & 5 & 1.25 & 40 & PRB & 40.34 \\
\hline 24 & 75 & 3 & 1.25 & 40 & PRB & 30.93 & 53 & 50 & 3 & 1.25 & 60 & PRB-nZVI & 50.06 \\
\hline 25 & 25 & 5 & 1.25 & 60 & PRB-nZVI & 87.68 & 54 & 75 & 5 & 0.5 & 40 & PRB & 44.81 \\
\hline 26 & 50 & 5 & 0.5 & 60 & PRB & 41.92 & 55 & 25 & 5 & 2 & 40 & PRB-nZVI & 87.72 \\
\hline 27 & 50 & 3 & 2 & 40 & PRB & 30.14 & 56 & 75 & 3 & 1.25 & 40 & PRB-nZVI & 41.59 \\
\hline 28 & 75 & 5 & 0.5 & 40 & PRB-nZVI & 72.15 & 57 & 25 & 5 & 1.25 & 60 & PRB & 32.72 \\
\hline 29 & 50 & 3 & 1.25 & 60 & PRB & 29.76 & 58 & 50 & 5 & 1.25 & 40 & PRB-nZVI & 82.22 \\
\hline
\end{tabular}

ferrous hydroxide and at the same time generates hydrogen gas (Li and Zhang, 2006, 2007):

$$
\mathrm{Fe}_{(\mathrm{s})}+2 \mathrm{H}_{2} \mathrm{O}_{(\mathrm{aq})} \rightarrow \mathrm{FeOOH}+1.5 \mathrm{H}_{2(\mathrm{~g})}
$$

According to the result of above equation, a core/shell structure is produced with zero-valent iron $\left(\mathrm{Fe}^{0}\right)$ as a core part and iron oxides/hydroxides as a shell layer (Li and Zhang, 2007). This special structure led to the nZVI having unique properties (high specific surface and redox potential) for pollutant removal. Previous studies have reported that for metals with a standard potential more positive than that of iron $\left(E^{0}=-0.41 \mathrm{~V}\right)$, such as $\mathrm{Cu}\left(E^{0}=0.34 \mathrm{~V}\right)$, the reduction and precipitation were the main mechanisms for contaminant removal (Li and Zhang, 2007; Huang et al., 2013). In contrast, for metals with a standard potential more negative or very close to that of iron, such as $\mathrm{Cd}\left(E^{0}=-0.40 \mathrm{~V}\right)$, the removal mechanism is purely sorption or complex formation; and there is no reduction of the metal ions on the surface (Li and Zhang, 2007). Thus, it could be suggested that the process of adsorption or complex formation was the main mechanism of $\mathrm{Cd}$ removal by nZVI surfaces in PRB-nZVI. Tan et al. (2016) reported that impregnation of functional nanoparticles, such as nZVI, onto pristine biochar after pyrolysis (biochar-based composites) could combine the advantages of biochar with the properties of functional nanoparticles. In addition, Sun et al. (2014) reported that Cd can be removed by biochar by three mechanisms: ion exchange, surface complexation, and surface precipitation or co-precipitation. So, it is expected that the composites obtained (coating of nZVI on biochar surfaces) show both good adsorption (via the nZVI part) and surface precipitation or co-precipitation (via the PRB part) of Cd on PRB-nZVI. Usman et al. (2016) evaluated the sorption process of date palm biochar (prepared at two pyrolysis temperatures of $300^{\circ} \mathrm{C}$ and $700^{\circ} \mathrm{C}$ ) for aqueous $\mathrm{Cd}$ removal. Their results showed that ion exchange with $\mathrm{Ca}$ and $\mathrm{Mg}$ and precipitation or co-precipitation (rather than surface complexation with oxygen-containing functional groups) are the main processes for $\mathrm{Cd}$ removal by biochar prepared at high pyrolysis temperature. A combination of sorption and precipitation (or co-precipitation) processes via nZVI 
and PRB, respectively, results in the generally high capacity or density per unit surface area for $\mathrm{Cd}$ retention. The use of nanomaterials on biochar surface can change HM adsorption through (1) changing on the surface functional groups of biochar and (2) improvement or deterioration on the pore property of biochar (Tan et al., 2016). Song et al. (2014) and Wang et al. (2015a) reported that addition of nanomaterials on the biochar increased the amount of oxygen-containing functional groups, in which higher adsorption of HMs occurred (Tan et al., 2016) by forming surface complexes, cation- $\pi$ bonding, electrostatic attraction, and ion exchange (Baig et al., 2014; Song et al., 2014; Wang et al., 2015a,b). Apart from the effect of nZVI, the high effectiveness in reducing the content of those contaminants is probably related with the large specific surface area and the numerous surface functional groups of biochar, which is of fundamental importance in the processes of adsorption of contaminants. In the present study, it seems that both the functional groups and nZVI on the surface of biochar could attend for Cd removal in aqueous solutions by the processes of sorption, precipitation, and co-precipitation.

As can be seen in Table 2, the maximum percentage of Cd removal obtained was $95.48 \%$, which was higher and lower than the maximum removal of $\mathrm{Cd}$ from an aqueous system reported by Wang et al. (2015a) and Doumer et al. (2016), respectively. According to the results, an empirical relationship was obtained between independent variables in uncoded units and $\mathrm{Cd}$ removal efficiency for each adsorbent: PRB (Equation 1) and PRBnZVI (Equation 2).

$$
\begin{aligned}
Y= & -4.08-0.75 X_{1}+21.13 X_{2}+2.06 X_{3}+0.44 X_{4}-0.09 X_{1} X_{2} \\
& +0.07 X_{1} X_{3}-0.002 X_{1} X_{4}-3.61 X_{2} X_{3}-0.02 X_{2} X_{4} \\
& -0.06 X_{3} X_{4}+0.01 X_{1}^{2}-0.29 X_{2}^{2}+7.2 X_{3}^{2}+0.003 X_{4}^{2} \\
Y= & -11.18-0.53 X_{1}+17.10 X_{2}+3.47 X_{3}+0.28 X_{4}-0.09 X_{1} X_{2} \\
& +0.07 X_{1} X_{3}-0.002 X_{1} X_{4}-3.61 X_{2} X_{3}-0.02 X_{2} X_{4} \\
& -0.06 X_{3} X_{4}+0.01 X_{1}^{2}-0.29 X_{2}^{2}+7.2 X_{3}^{2}+0.003 X_{4}^{2}
\end{aligned}
$$

In addition, the relationship between response and variables in coded units has been expressed by the following Equation 3:

$$
\begin{aligned}
Y= & 50.46-3.81 X_{1}+12.78 X_{2}+0.4 X_{3}+1.51 X_{4}-14.93 X_{5} \\
& +4.66 X_{1} X_{2}+1.33 X_{1} X_{3}-1.16 X_{1} X_{4}+2.66 X_{1} X_{5}-5.41 X_{2} X_{3} \\
& -0.65 X_{2} X_{4}-4.03 X_{2} X_{5}-0.84 X_{3} X_{4}-2.07 X_{3} X_{5} \\
& -7.17 X_{4} X_{5}+5.99 X_{1}^{2}-1.16 X_{2}^{2}+4.04 X_{3}^{2}+1.32 X_{4}^{2}
\end{aligned}
$$

where $X_{1}, X_{2}, X_{3}, X_{4}$, and $X_{5}$ are Cd concentration, $\mathrm{pH}$, adsorbent dosage, contact time, and type of adsorbent, respectively.

Analysis of variance (ANOVA) fitted on quadratic model is used to check the statistical suitability of the model based on the significance of the independent variables (in coded units) and their interactions (Table 3) by the Student's $t$ test and $p$ values.

According to the results, the achieved values of probability $>F$ less than 0.05 indicated that the model is statistically significant. In addition, the values of $R^{2}$ and adjusted $R^{2}$ are close to each other, which are relatively high and have supported an acceptable correlation between the observed and predicted values. The probability of lack of fit greater than 0.05 also indicates that the BBM used in this study is statistically significant for the response and it is suitable for further analysis.

\section{Prediction of response surface for maximum Cd removal}

According to the results obtained from the previous section, the BBM as an experimental design model under RSM was a suitable model for estimating the effects of independent variables and their interactions on $\mathrm{Cd}$ removal in an aqueous solution. Therefore, for the purpose of precise examination of the interactions of four independent factors on the removal of $\mathrm{Cd}$ in aqueous media, a three-dimensional representation and contour diagrams of interaction effects were drawn and discussed.

\section{Effect of initial $\mathrm{Cd}$ concentration and $\mathrm{pH}$}

The effects of the simultaneous variation of initial $\mathrm{Cd}$ concentration and $\mathrm{pH}$, under predefined conditions (adsorbent dosage, $1.25 \mathrm{~g} \mathrm{~L}^{-1}$; time, $40 \mathrm{~min}$; adsorbent type, PRB-nZVI), on Cd removal are shown in the form

Table 3: ANOVA for quadratic model for $\mathrm{Cd}$ removal.

\begin{tabular}{lrrrrr}
\hline $\begin{array}{l}\text { Sources of } \\
\text { variation }\end{array}$ & $\begin{array}{r}\text { Sum of } \\
\text { squares }\end{array}$ & $\boldsymbol{d f}$ & $\begin{array}{r}\text { Mean } \\
\text { square }\end{array}$ & $\boldsymbol{F}$ value & Probability $>\boldsymbol{F}$ \\
\hline Model & 20307.00 & 19 & 1068.79 & 4.60 & $<0.0001$ \\
Residual & 8824.92 & 38 & 232.23 & & \\
Lack of fit & 5061.58 & 29 & 174.54 & 0.42 & 0.9639 \\
Pure error & 3763.34 & 9 & 418.15 & & \\
Total & 29131.92 & 57 & & & \\
\hline
\end{tabular}

$R^{2}=0.797 ;$ adjusted $R^{2}=0.745 ;$ predicted $R^{2}=0.601 ; \mathrm{CV}=27.95 \%$. $d f$, degree of freedom. 
of three-dimensional diagrams and contours in Figure 4. $\mathrm{Cd}$ removal efficiency increased with the increase and decrease of the initial solution $\mathrm{pH}$ and initial $\mathrm{Cd}$ concentration, respectively. As can be seen in the figure, the maximum removal of $\mathrm{Cd}$ was obtained with $\mathrm{pH} 7$ and initial Cd concentration $25 \mathrm{mg} \mathrm{L}^{-1}$. For example, at $\mathrm{pH} 3$ and initial Cd concentration $75 \mathrm{mg} \mathrm{L}^{-1}$, the removal efficiency of $\mathrm{Cd}$ reached $58.45 \%$, which increased to $98.18 \%$ with $\mathrm{pH} 7$ and initial Cd concentration $25 \mathrm{mg} \mathrm{L}^{-1}$. By increasing the concentration of $\mathrm{Cd}$, the adsorption rate decreased, which can be attributed to the saturation of the available surfaces of adsorbent for adsorbate molecules (Salmani et al., 2012). Similar findings have been published by Savasari et al. (2015), Boparai et al. (2011), and Rao et al. (2012) for Cd removal. Decrease in solution pH caused a decrease in $\mathrm{Cd}$ removal. In low $\mathrm{pH}$, because of high concentrations of hydrogen ions, there is a strong competition between $\mathrm{Cd}$ and $\mathrm{H}^{+}$to occupy the active metal-binding sites, which reduces adsorption of $\mathrm{Cd}$ on the adsorbent (Rao et al., 2010; Boparai et al., 2011). Furthermore, in low levels of $\mathrm{pH}$, the thickness of the double layer between the adsorbent and the solution significantly decreases, which inhibits Cd adsorption (Park et al., 2008). Previous researches have shown that by decreasing and increasing the $\mathrm{pH}$, the positive and negative surface charge of nZVI is increased, respectively (Sharma, 2008; Savasari et al., 2015), which is another reason why Cd adsorption is increased with increasing pH. Usman et al. (2016) stated that 'the negative surface charge of the biochar can be increased by increasing the $\mathrm{pH}$, mainly due to deprotonation of hydroxyl and carboxylic groups, thus enhancing the adsorption of positively charged $\mathrm{Cd}$ through electrostatic forces of attraction.' Göksungur et al. (2005), Ghorbani et al. (2013), and Boparai et al. (2011) observed that Cd removal by adsorbent increased with increases in solution $\mathrm{pH}$; and the maximum $\mathrm{Cd}$ removal was obtained at $\mathrm{pH} \mathrm{6,5}$, and 8, respectively.

\section{Effect of initial Cd concentration and adsorbent dosage}

Figure 5 illustrates the combined effect of initial Cd concentration and adsorbent dosage on the Cd removal

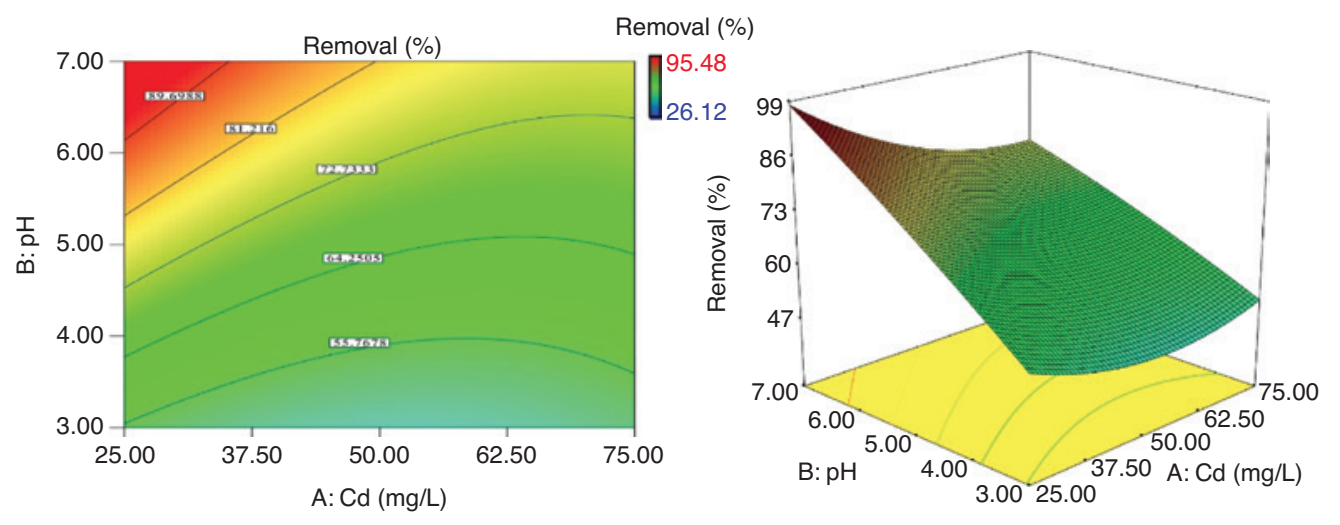

Figure 4: The contour and three-dimensional diagrams of $\mathrm{Cd}$ removal efficiency (\%) as a function of initial $\mathrm{Cd}$ concentration and $\mathrm{pH}$.

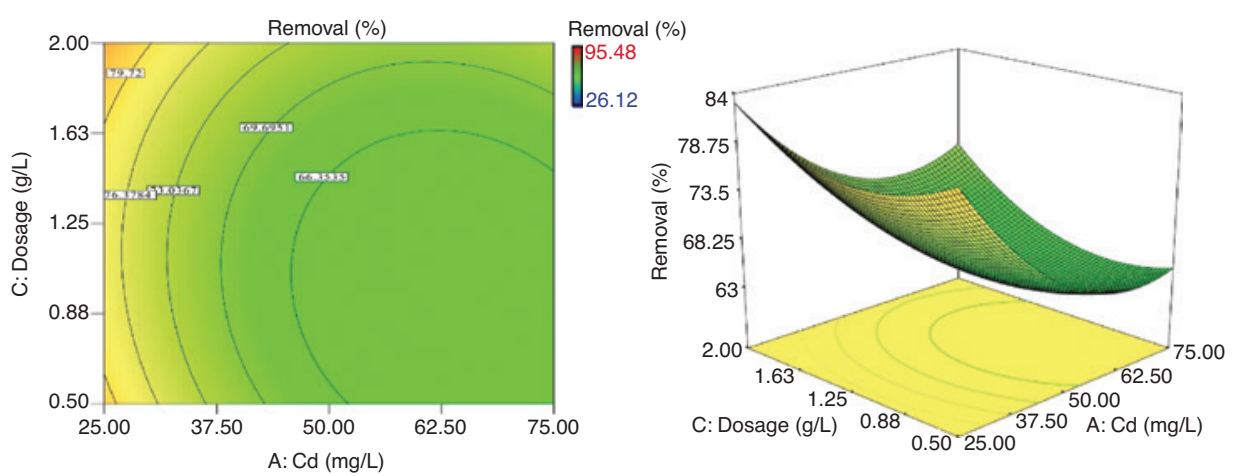

Figure 5: The contour and three-dimensional diagrams of $\mathrm{Cd}$ removal efficiency (\%) as a function of initial Cd concentration and adsorbent dosage. 
percentage under the predefined conditions ( $\mathrm{pH} 5$; time, 40 min; adsorbent type, PRB-nZVI). The graphs show that increasing adsorbent dosage and decreasing the initial $\mathrm{Cd}$ concentration led to an increase in Cd removal efficiency. Maximum Cd removal (83.06) was observed at adsorbent dosage $2 \mathrm{~g} \mathrm{~L}^{-1}$ and initial Cd concentration $25 \mathrm{mg} \mathrm{L}^{-1}$. By increasing the adsorbent dosage, the special contact surface and the availability of empty active sites for the adsorption of Cd increase (Chen et al., 2011; Chowdhury and Saha, 2013).

\section{Effect of initial $\mathrm{Cd}$ concentration and time contact}

The interaction effect of initial Cd concentration and time contact is shown in Figure 6. As expected, the Cd removal efficiency increased with increases in contact time because of increasing available contact surfaces for $\mathrm{Cd}$
(Bhatti et al., 2018). The maximum removal capacity was found at initial Cd concentration $25 \mathrm{mg} \mathrm{L}^{-1}$ and $60 \mathrm{~min}$.

\section{Effect of $\mathrm{pH}$ and adsorbent dosage}

Increasing the $\mathrm{pH}$ from 3 to 7 facilitated the removal of $\mathrm{Cd}$ (Figure 7). In low pH value (3), removal efficiency increases with increasing adsorbent dosage, but in high $\mathrm{pH}$ value (7), removal efficiency was maximum in low dosage of adsorbent and afterward shows a slight decrease in predefined conditions (initial Cd concentration, $50 \mathrm{mg} \mathrm{L}^{-1}$; time, $40 \mathrm{~min}$; adsorbent type, PRB-nZVI), which might be because the adsorptive capacity of the adsorbent available was not fully used at a higher adsorbent dosage compared with lower adsorbent dosage. Therefore, it might be possible that adsorption capacity decreases as adsorbent dosage increases. In addition, an increase in the adsorbent dosage might cause aggregation of adsorbent,

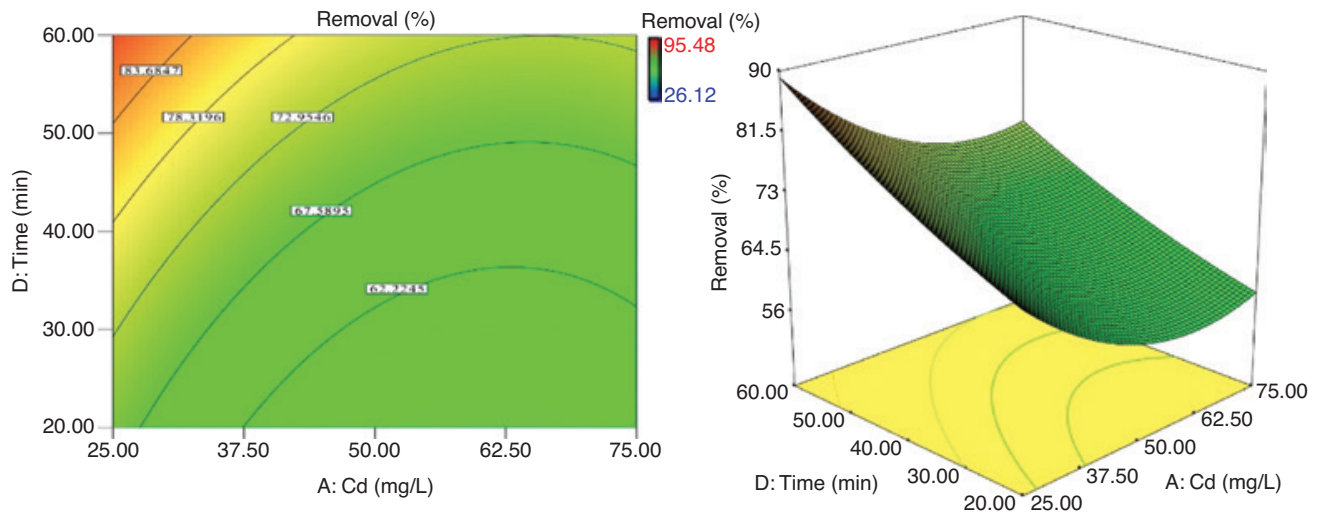

Figure 6: The contour and three-dimensional diagrams of $\mathrm{Cd}$ removal efficiency (\%) as a function of initial Cd concentration and contact time.

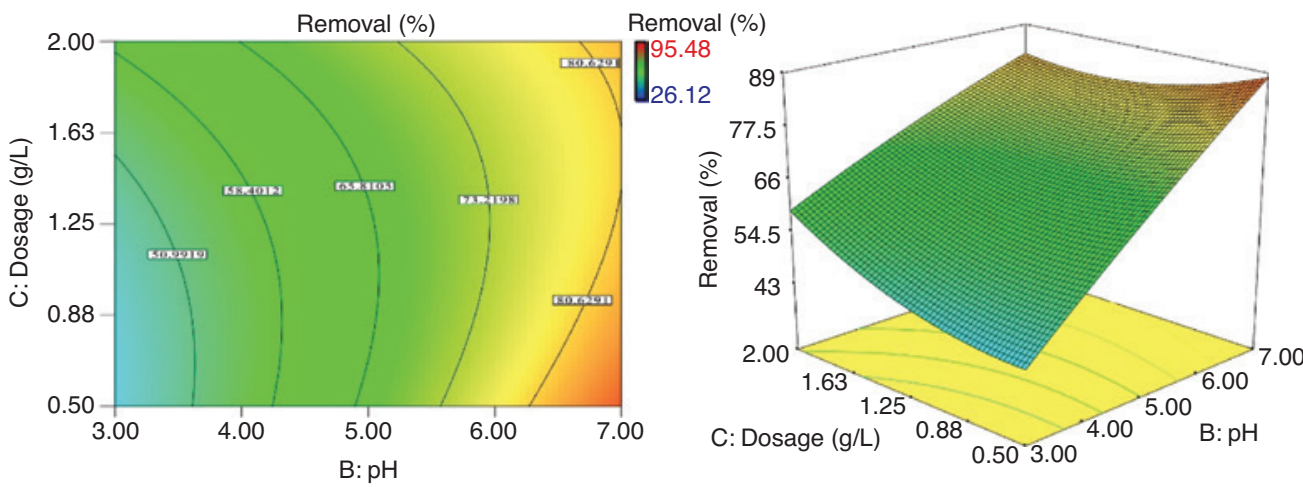

Figure 7: The contour and three-dimensional diagrams of $\mathrm{Cd}$ removal efficiency (\%) as a function of $\mathrm{pH}$ and adsorbent dosage. 
and consequently, the available adsorption sites might decrease as well because of the adsorption density.

\section{Effect of pH and contact time}

Figure 8 shows the effect of $\mathrm{pH}$ and contact time on $\mathrm{Cd}$ removal efficiency. $\mathrm{Cd}$ removal showed to be very sensitive to changes in the solution $\mathrm{pH}$. The removal capacity of $\mathrm{Cd}$ sharply increased when the $\mathrm{pH}$ of the solution increased from 3 to 7 . According to the results, the maximum $\mathrm{Cd}$ removal was obtained at $\mathrm{pH} 7$, whereas under acidic conditions, little removal occurred. In contrast, contact time compared to the $\mathrm{pH}$ has little effect on the Cd removal; however, with increasing contact time, an increase in $\mathrm{Cd}$ removal was observed. The maximum removal capacity was found to be $60 \mathrm{~min}$ at $\mathrm{pH} 7$.

\section{Effect of contact time and adsorbent dosage}

The effects of contact time and adsorbent dosage on the $\mathrm{Cd}$ removal are shown in Figure 9. Increasing both contact time and of adsorbent dosage from 20 to $60 \mathrm{~min}$ and $0.5-2 \mathrm{~g} \mathrm{~L}^{-1}$, respectively, facilitated the removal of $\mathrm{Cd}$. The combined effect of contact time and adsorbent dosage has been predicted that the points of maxima for contact time and adsorbent dosage are at $60 \mathrm{~min}$ and $2 \mathrm{~g} \mathrm{~L}^{-1}$, respectively.

\section{Desirability process}

Optimization of Cd removal and desirability of model were obtained using numerical optimization. To get desirable goals, which are combined into an overall desirability function, for each independent factor and response, different goals including maximize, minimize, target, within range, and set to an exact value (factors only) could be used as desired goals in the study. In the current study, based on the different goals, two estimations were assessed. In the first test, the independent variables were given within range, whereas the response was planned to a maximum. As a result, 30 solutions for the optimum conditions were generated according to the order of suitability. The first 10 solutions for the best conditions were

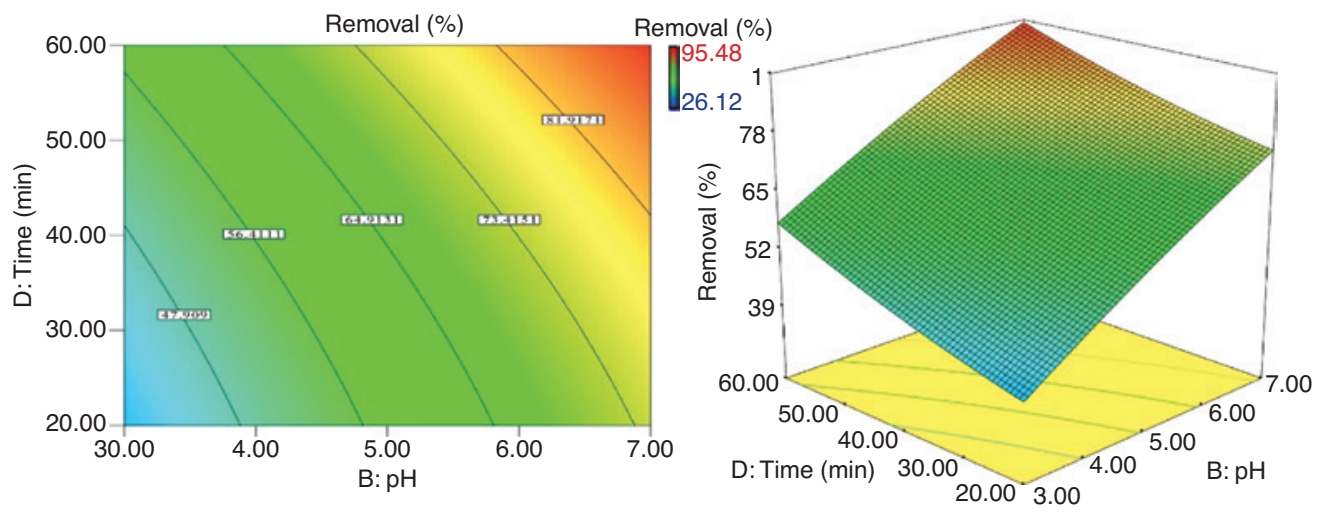

Figure 8: The contour and three-dimensional diagrams of $\mathrm{Cd}$ removal efficiency (\%) as a function of $\mathrm{pH}$ and contact time.

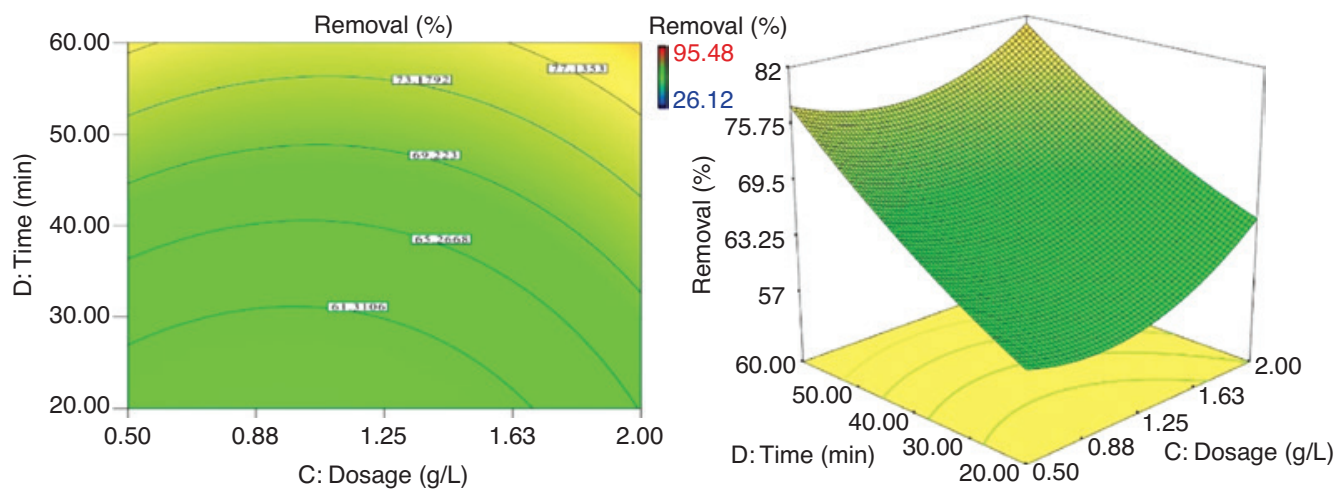

Figure 9: The contour and three-dimensional diagrams of $\mathrm{Cd}$ removal efficiency (\%) as a function of contact time and adsorbent dosage. 
Table 4: Experimental results for model validation conducted at the optimum conditions as obtained from BBM.

\begin{tabular}{|c|c|c|c|c|c|c|c|}
\hline \multirow[t]{2}{*}{ Solution } & \multicolumn{5}{|c|}{ Within range } & \multirow{2}{*}{$\frac{\text { Maximum }}{\text { Cd removal predication }}$} & \multirow[t]{2}{*}{ Desirability } \\
\hline & $x_{1}$ & $x_{2}$ & $x_{3}$ & $x_{4}$ & $x_{5}$ & & \\
\hline \multicolumn{8}{|l|}{ First test } \\
\hline 1 & 25.99 & 6.58 & 0.55 & 34.11 & PRB-nZVI & 96.85 & 1 \\
\hline 2 & 46.54 & 6.89 & 0.53 & 55.29 & PRB-nZVI & 95.96 & 1 \\
\hline 3 & 32.4 & 6.83 & 1.47 & 59.41 & PRB-nZVI & 99.35 & 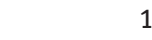 \\
\hline 4 & 25.9 & 6.58 & 1.95 & 46.12 & PRB-nZVI & 96.68 & 1 \\
\hline 5 & 43.6 & 6.82 & 0.55 & 58.69 & PRB-nZVI & 98.74 & 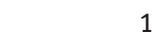 \\
\hline 6 & 33.92 & 6.94 & 1.98 & 51.87 & PRB-nZVI & 95.68 & . \\
\hline 7 & 25.9 & 6.61 & 1 & 46 & PRB-nZVI & 98.08 & 1 \\
\hline 8 & 34.73 & 6.76 & 0.8 & 55.05 & PRB-nZVI & 99.10 & 1 \\
\hline 9 & 40.73 & 6.86 & 0.51 & 52.17 & PRB-nZVI & 97.98 & 1 \\
\hline 10 & 37.32 & 6.85 & 1.54 & 59.74 & PRB-nZVI & 95.84 & 1 \\
\hline \multirow[t]{2}{*}{ Solution } & Maximum & Within range & Minimum & \multicolumn{2}{|c|}{ Within range } & Maximum & Desirability \\
\hline & $x_{1}$ & $x_{2}$ & $x_{3}$ & $x_{4}$ & $x_{5}$ & Cd removal predication & \\
\hline \multicolumn{8}{|c|}{ Second test } \\
\hline 1 & 75 & 7 & 0.5 & 60 & PRB-nZVI & 90.61 & 0.967 \\
\hline 2 & 75 & 7 & 0.5 & 59.54 & PRB-nZVI & 37.52 & 0.966 \\
\hline 3 & 75 & 6.97 & 0.5 & 60 & PRB-nZVI & 90.36 & 0.966 \\
\hline 4 & 75 & 7 & 0.5 & 59.30 & PRB-nZVI & 90.25 & 0.965 \\
\hline 5 & 74.23 & 7 & 0.5 & 60 & PRB-nZVI & 90.64 & 0.964 \\
\hline 6 & 75 & 7 & 0.5 & 59.17 & PRB-nZVI & 90 & 0.961 \\
\hline 7 & 73.55 & 7 & 0.5 & 60 & PRB-nZVI & 90.73 & 0.960 \\
\hline 8 & 74.62 & 7 & 0.5 & 58.34 & PRB-nZVI & 89.79 & 0.960 \\
\hline 9 & 75 & 7 & 0.5 & 57.50 & PRB-nZVI & 89.3 & 0.958 \\
\hline 10 & 73.64 & 7 & 0.5 & 58.14 & PRB-nZVI & 89.76 & 0.954 \\
\hline
\end{tabular}

selected as shown in Table 4. The maximum Cd removal efficiency obtained was $96.85 \%$ at a Cd initial concentration of $25.92 \mathrm{mg} \mathrm{L}^{-1}$, $\mathrm{pH}$ of 6.85, adsorbent (PRB-nZVI) dose of $0.55 \mathrm{~g} \mathrm{~L}^{-1}$, and contact time of $34.11 \mathrm{~min}$, with desirability of 1 . Figure $10 \mathrm{~A}$ (optimal factor settings and optimal response prediction are shown with red and blue points, respectively) presents a ramp function graph of desirability made from 58 optimum points via the numerical optimization in the first test. In the second test, the maximum level of the initial $\mathrm{Cd}$ concentration $\left(75 \mathrm{mg} \mathrm{L}^{-1}\right)$, the minimum level of the adsorbent dosage $(0.5 \mathrm{~g} / \mathrm{L})$, the level of the $\mathrm{pH}$ within the range of $2-7$, the contact time within the range of 20-60 $\mathrm{min}$, and the Cd removal efficiency were set for the maximum desirability by both adsorbents (PRB and PRB-nZVI). The maximum Cd removal was found at a Cd initial concentration of $75 \mathrm{mg} \mathrm{L}^{-1}$, $\mathrm{pH}$ of 7, adsorbent dose of $0.5 \mathrm{~g} \mathrm{~L}^{-1}$, and contact time of $60 \mathrm{~min}$; the Cd removal and the desirability obtained were $90.61 \%$ and 0.967 , respectively (Figure 10B). The high desirability obtained $(>0.954)$ indicates that the predicted function could express the desired conditions and the experimental model. To better understand the proposed modeling, examples of the contour diagrams of $\mathrm{Cd}$ removal efficiency (\%) at maximum desirability value and different types of goals are given in Figure 11. Figure 11A shows that $\mathrm{Cd}$ maximum removal of $96.17 \%$ was achieved in the initial Cd concentration of $38.11 \mathrm{mg} \mathrm{L}^{-1}$, $\mathrm{pH}$ of 7, adsorbent dose $0.5 \mathrm{~g} \mathrm{~L}^{-1}$, and contact time of $41.86 \mathrm{~min}$, with the desirability of 1 . In another example, the maximum $\mathrm{pH}$ (7) and other independent variables in regulation range as well as the maximum adsorption of $\mathrm{Cd}$ showed that the maximum adsorption of $\mathrm{Cd}$ value of $98.71 \%$ was achieved in the initial $\mathrm{Cd}$ concentration of $27.56 \mathrm{mg} \mathrm{L}^{-1}$, adsorption dose of $1.61 \mathrm{~g} \mathrm{~L}^{-1}$, and contact time of $48.43 \mathrm{~min}$, with the desirability of 1 (Figure 11B). Figure $11 \mathrm{C}$ and D shows maximum removal of $\mathrm{Cd}$ by adsorbent type of PRB-nZVI and PRB, respectively (other variables were regulated in the range). The maximum value of Cd removal (98.51\%) with PRB-nZVI adsorbent was achieved in the initial Cd concentration of $26.51 \mathrm{mg} \mathrm{L}^{-1}$, $\mathrm{pH}$ of 6.96 , adsorbent dose of $1.18 \mathrm{~g} \mathrm{~L}^{-1}$, and contact time of $43.9 \mathrm{~min}$, with desirability of 1 (Figure 11C). In contrast, the maximum removal of $\mathrm{Cd}(73.0 \%)$ with PRB adsorbent was achieved in the initial Cd concentration of $25 \mathrm{mg} \mathrm{L}^{-1}$, $\mathrm{pH}$ of 7 , adsorbent dose of $0.5 \mathrm{~g} \mathrm{~L}^{-1}$ and contact time of $20 \mathrm{~min}$, with desirability of 0.67 (Figure 11D). Savasari et al. (2015) studied 
A

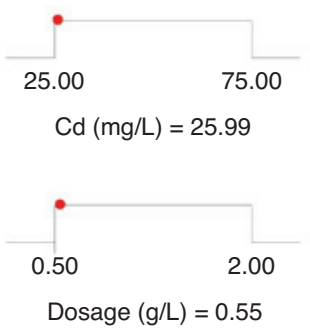

Treatment B

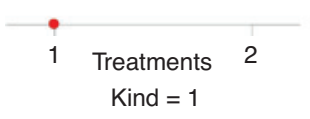

Desirability $=1.000$
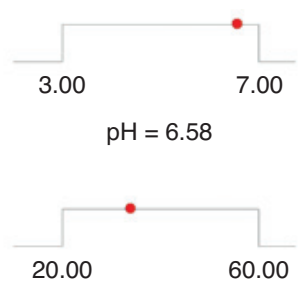

Time $(\min )=34.11$

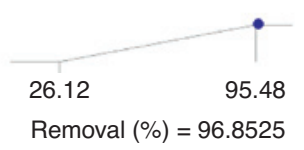

Removal $(\%)=96.8525$
B
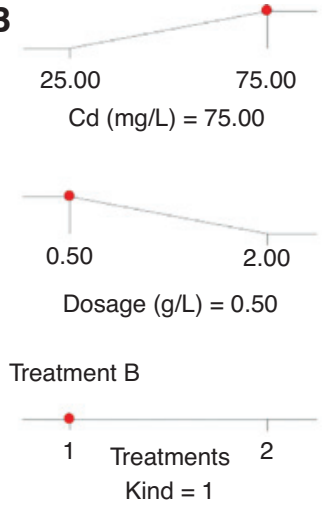

Desirability $=0.967$
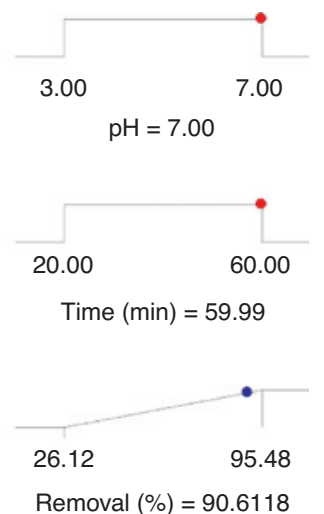

Figure 10: Desirability ramp for the optimization of the response and the variables (A, first test; B, second test).

\section{A}

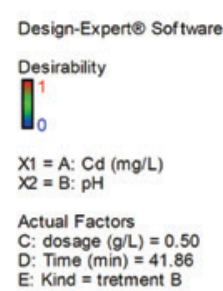

D: Time $(\min )=41.86$
E: Kind $=$ tretment B
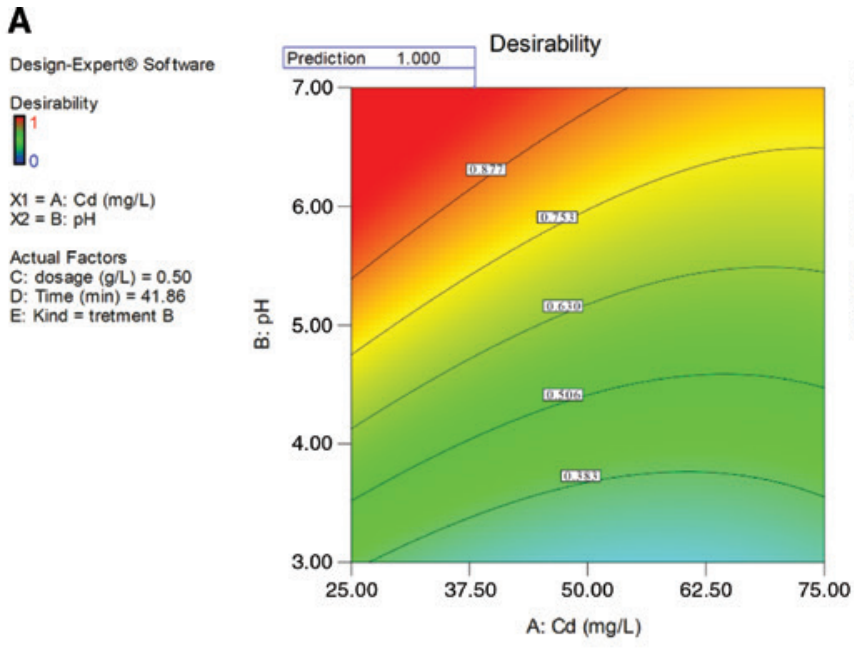

\section{C}

Design-Experte Sof tware

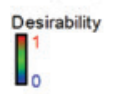

$X_{1}=A: C d(m g / L)$

$X 2=B: p H$

Actual Factors

C: dosage $(g / L)=1.18$

E: Kind $=$ tretment $B$

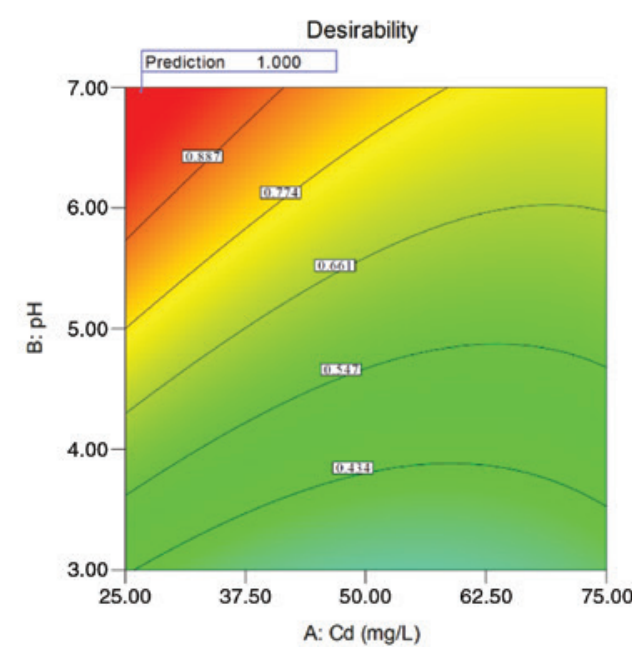

B

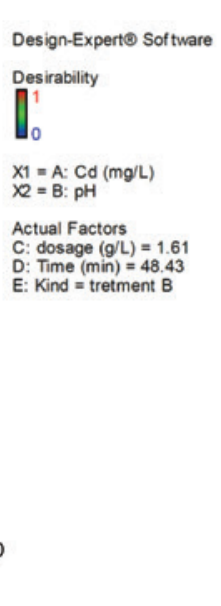

D

Design-Experto Sof tware

$\prod^{1}{ }^{1}$

U.

$X_{1}=A: C d(m g / L)$

$\mathrm{X}=\mathrm{B}: \mathrm{pH}$

C: dosage $(g / L)=0.50$

D: Time $($ min $)=20.00$

Kind $=$ non-terat B
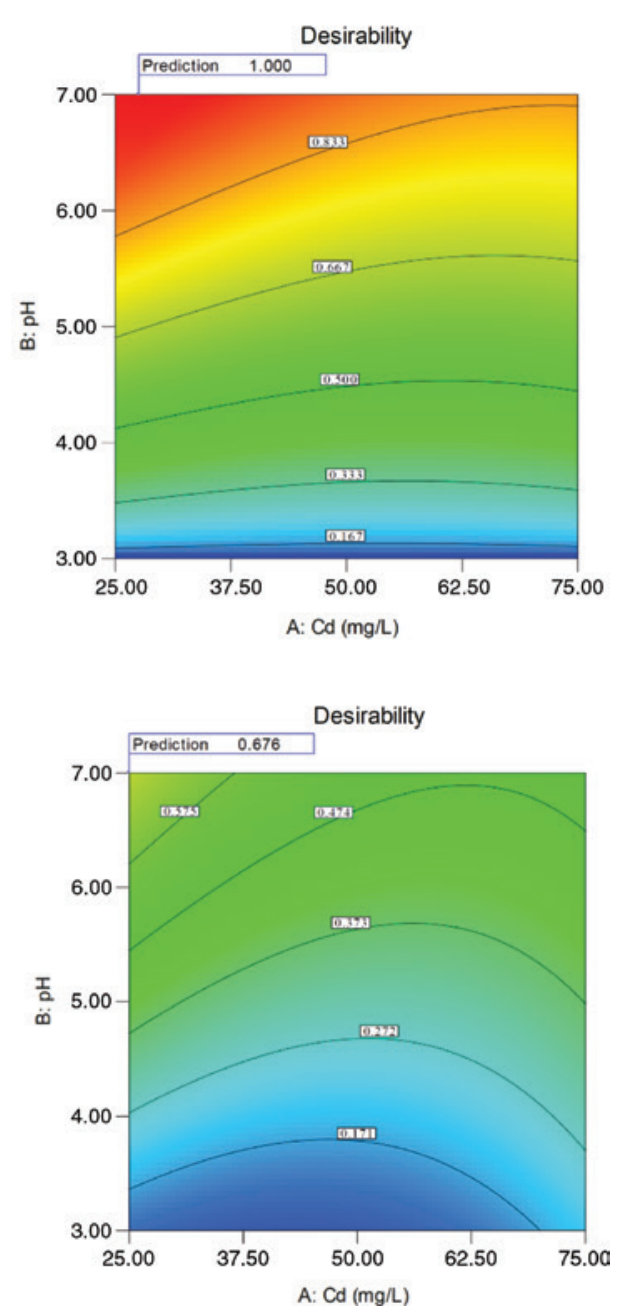

Figure 11: Contour graphs at maximum desirability and different types of goals.

The contour diagrams of $\mathrm{Cd}$ removal efficiency (\%) at maximum desirability value and different types of goals (A, all independent variables $=$ within range and response $=$ maximum; $\mathrm{B}, \mathrm{pH}=$ maximum and other independent variables $=$ within range and response $=$ maximum; $C$, all independent variables $=$ within range and adsorbent $=$ PRB-nZVI; D, all independent variables $=$ within range and adsorbent $=$ PRB). 
the optimization of $\mathrm{Cd}$ removal from an aqueous solution by nZVI using RSM. Their numerical optimization results revealed that the optimum removal $(79.68 \%)$ was obtained at nZVI dosage of $2 \mathrm{~g} \mathrm{~L}^{-1}$, initial Cd concentration of $15 \mathrm{mg} \mathrm{L}^{-1}$, contact time of $60 \mathrm{~min}$, and $\mathrm{pH}$ of 7. Rao et al. (2012) found that maximum Cd removal of $93.2 \%$ by waste agricultural biosorbent was obtained at initial $\mathrm{Cd}$ concentration of $40.15 \mathrm{mg} \mathrm{L}^{-1}$, adsorbent dosage of $0.5 \mathrm{~g} / 50 \mathrm{~mL}$ solution, $\mathrm{pH}$ of 5.0 , and temperature of $35^{\circ} \mathrm{C}$, with value of desirability factor 1.

\section{Conclusion}

Release of Cd into the environment by wastewaters disposed from industries can cause serious health problems. Hence, the removal of $\mathrm{Cd}$ from industrial wastewaters is essential before discharge. Nowadays, the application of nanoengineered biochars is developed to improve biochar sorption properties for removing HMs from a contaminated aqueous solution. This research was carried out to produce and characterize the new composite biochar coated by nZVI and then test its efficiency on Cd removal from a spiked aqueous solution using BBM under the RSM. The performance of prepared PRB and PRB-nZVI to eliminate $\mathrm{Cd}$ from aqueous solutions was examined in batch tests, where numerous parameters including initial $\mathrm{Cd}$ concentration, contact time, solution $\mathrm{pH}$, adsorbent dosage, and type of adsorbents were considered. The results showed that the performance of the new composite of biochar (PRB-nZVI) was better than the pristine biochar (PRB) for Cd removal from an aqueous solution. Both the functional groups and nZVI on the surface of biochar could attend for Cd removal in aqueous solutions by processes of sorption, precipitation, and co-precipitation. The maximum Cd removal efficiency obtained was $97.58 \%$ at a Cd initial concentration of $25.99 \mathrm{mg} \mathrm{L}^{-1}$, $\mathrm{pH}$ of 6.58 , adsorbent (PRB-nZVI) dose of $0.55 \mathrm{~g} \mathrm{~L}^{-1}$, and contact time of $34.11 \mathrm{~min}$, with desirability of 1 . Generally, according to the results, PRBnZVI could be suitable as a sorbent for the removal of $\mathrm{Cd}$ from industrial wastewater.

\section{Experimental}

\section{Chemicals}

The chemicals used in this study, including iron sulfate heptahydrate $\left(\mathrm{FeO}_{4} \mathrm{~S} \cdot 7 \mathrm{H}_{2} \mathrm{O}\right)$, sodium borohydride $\left(\mathrm{NaBH}_{4}\right)$, hydrochloric acid fuming $37 \%(\mathrm{HCl})$, and sodium hydroxide $(\mathrm{NaOH})$, and except for Cd nitrate, were purchased from Merck (Darmstadt, Germany). Cadmium nitrate $\left(\mathrm{Cd}\left(\mathrm{NO}_{3}\right)_{2} \cdot 4 \mathrm{H}_{2} \mathrm{O}\right)$ was purchased from Scharlau Products Co (Barcelona, Spain). All solutions were prepared using distilled water.

\section{Preparation and characterization of adsorbents}

The PR were used as raw feedstocks to produce biochar. For this purpose, firstly, the PR were washed with distilled water several times and dried in an air-forced oven at $60^{\circ} \mathrm{C}$ for $48 \mathrm{~h}$. Then, the samples were chopped and passed through a 4-mm sieve. Raw feedstocks were pyrolyzed in a muffle furnace, under a limited oxygen condition, for $4 \mathrm{~h}$ at $500^{\circ} \mathrm{C}$ to produce biochars. To provide oxygen-limiting conditions, pure nitrogen gas was injected into the muffle furnace at a flow rate of $5 \mathrm{~L} \mathrm{~min}^{-1}$ for $5 \mathrm{~min}$. Biochar $\mathrm{EC}$ and $\mathrm{pH}$ were measured using a 1:5 solid/water ratio after shaking for $30 \mathrm{~min}$ (Singh et al., 2010). Elemental C, N, H, and S abundances were determined, using a CHNS Elemental Analyzer (Hesse, Germany) (vario MACRO CHNS). PRB-nZVI was produced according to the producers reported by Quan et al. (2014a). According to the reported method, initially, the pretreatment process will be performed on biochar samples. For this purpose, $10.0 \mathrm{~g}$ of the biochar was added to $250 \mathrm{~mL}$ of sulfuric acid $(0.05 \mathrm{M})$ at $45^{\circ} \mathrm{C}$ for $48 \mathrm{~h}$ under mechanical stirring at $300 \mathrm{rpm}$, and then washed with distilled water and dried. In next stage, based on a conventional liquid-phase method, $2 \mathrm{~g}$ of pretreated biochar was suspended in $60 \mathrm{~mL}(1.0 \mathrm{M}) \mathrm{FeSO}_{4}$ and stirred for $2 \mathrm{~h}$ to let the biochar adsorb $\mathrm{Fe}^{2+}$. Then, $90 \mathrm{~mL}$ ethanol (50\%) was added, and $100 \mathrm{~mL}$ $(0.4 \mathrm{M})$ of sodium borohydride was added drop by drop (one drop per $2 \mathrm{~s}$ ) to the suspension and continuously stirred for $2 \mathrm{~h}$ to complete the reaction. To prevent oxidation, all of the above steps were done in the presence of nitrogen gas. At the end, the suspension was centrifuged and washed three times with pure ethanol (96\%) to avoid the immediate oxidation of PRB-nZVI (Shi et al., 2011; Quan et al., 2014a) and put in a vacuum drying oven at $60^{\circ} \mathrm{C}$ for $8 \mathrm{~h}$. Finally, the prepared PRB-nZVI was stored inside the glove box before use. The structure of PRB and PRB-nZVI was examined with X-ray diffraction [Bruker D8 Advance X-ray diffractometer (Karlsruhe, Germany) with CuKo radiation operated at $40 \mathrm{kV}$ and $40 \mathrm{~mA}$ ], FTIR (TENSOR II from Bruker, Germany), and field emission scanning electron microscope TESCAN FE-SEM MIRA3 (TESCAN, Czech Republic).

\section{Batch experiments}

A series of batch experiments were conducted to determine the effects of independent variables (initial Cd concentration, solution $\mathrm{pH}$, type of adsorbents, contact time, and dosage of adsorbents) on $\mathrm{Cd}$ removal from Cd-polluted aqueous solutions. For this purpose, a 25-mL solution containing different levels of $\mathrm{Cd}\left(25,50\right.$, and $\left.75 \mathrm{mg} \mathrm{L}^{-1}\right)$ with the desired $\mathrm{pH}(3,5$, and 7 ; set by $0.1 \mathrm{M} \mathrm{NaOH}$ and $0.1 \mathrm{M} \mathrm{HCl} \mathrm{solu-}$ tions) was poured into centrifuge tubes, and the prepared adsorbents (PRB and PRB-nZVI) at different dosages $\left(0.5,1.5\right.$, and $\left.2 \mathrm{~g} \mathrm{~L}^{-1}\right)$ were added to each tube separately. The tubes were shaken vigorously for 20,40 , and $60 \mathrm{~min}$ at $25^{\circ} \mathrm{C}$ and then centrifuged at $3000 \mathrm{rpm}$. The supernatant was filtered, and the concentration of $\mathrm{Cd}$ in the clear extract solution was determined using atomic absorption spectrophotometer Varian SpectrAA-10 (Palo Alto, CA, USA). The percentage of $\mathrm{Cd}$ removal $(R)$ was calculated as: 


$$
R=\frac{C_{\mathrm{i}}-C_{\mathrm{f}}}{C_{\mathrm{i}}} \times 100
$$

where $C_{\mathrm{i}}$ and $C_{\mathrm{f}}$ are initial and final $\mathrm{Cd}$ concentrations $\left(\mathrm{mg} \mathrm{L}^{-1}\right)$, respectively.

\section{Experimental design and optimization of the adsorption process using the RSM approach}

In the present study, the BBM under RSM was used as the experimental design model to determine the optimum condition of $\mathrm{Cd}$ removal from a contaminated aqueous solution. The RSM has been introduced as an operative model that contains a group of dedicated empirical techniques for the prediction of relationship between a group of controlled investigational factors and measured responses according to one or more selected criteria. BBMs are rotatable or nearly rotatable secondorder designs based on three-level incomplete factorial designs (Box and Behnken, 1960). For a three-factor BBM, its graphical representation can be seen as a cube that consists of the central point and the middle points of the edges (Myers and Montgomery, 2002; Ferreira et al., 2007). Optimization experiments were carried out by evaluation of the effect of four variables (Cd concentration, solution $\mathrm{pH}$, contact time, and dosage of adsorbents) at three levels (high, medium and low), and one category contained two variables (PRB and PRB-nZVI). Codification of the levels of the independent variables, that is, converting the real value into coordinates inside a scale with dimensionless values, was done according to the following equation:

where

$$
x_{\mathrm{i}}=\frac{X_{\mathrm{i}}-X_{0}}{\Delta X_{\mathrm{i}}}
$$

$x_{\mathrm{i}}$ : dimensionless value of an independent variable

$X_{\mathrm{i}}$ : real value of an independent variable

$X_{0}$ : value of an independent variable at the center point

$\Delta X_{\mathrm{i}}$ : step change

The number of experiments required by the BBM was determined from the equation $N=2 K(K-1)+C$, where $N$ is the number of test samples, $K$ is the number of variables (four variables), and $C$ is the number of central points (five central points). In this study, the total number of experiments based on the BBM was 58 tests ( 29 tests for PRB and 29 tests for PRB-nZVI). An empirical second-order polynomial model is used to determine the relationship between removal efficiency of $\mathrm{Cd}$ (as the dependent variable) and behavior of the system (as the independent variable), which is expressed as:

$$
Y=\alpha+\sum \beta_{\mathrm{i}} X_{\mathrm{i}}+\sum \beta_{\mathrm{ii}} X_{\mathrm{i}}^{2}+\sum \beta_{\mathrm{ij}} X_{\mathrm{i}} X_{\mathrm{j}}+\varepsilon
$$

where $Y$ is the response, and $\alpha, \beta_{\mathrm{i}}$, and $\beta_{\mathrm{ii}}$ are the regression coefficients of variables for intercept, linear, quadratic, and interaction terms, respectively. $X_{\mathrm{i}}$ and $X_{\mathrm{i}}$ are the independent variables, and $\varepsilon$ is the residual term. Regression equations and response surface plots of RSM for identification of optimum conditions of Cd removal were generated using the Design-Expert software (Silicon Valley, CA, USA) (version 7.00).

Acknowledgments: This work has been financially supported by the Institute of Science and High Technology and Environmental Sciences, Graduate University of Advanced Technology, Kerman, Iran.

\section{References}

Ahmad, M.; Rajapaksha, A. U.; Lim, J. E.; Zhang, M.; Bolan, N.; Mohan, D.; Vithanage, M.; Lee, S. S.; Ok, Y. S. Biochar as a sorbent for contaminant management in soil and water: a review. Chemosphere 2014, 99, 19-33.

Ahmad, M.; Ahmad, M.; Usman, A. R.; Al-Faraj, A. S.; Abduljabbar, A. S.; Al-Wabel, M. I. Biochar composites with nano zerovalent iron and eggshell powder for nitrate removal from aqueous solution with coexisting chloride ions. Environ. Sci. Pollut. Res. 2018, 25, 25757-25771.

Alidokht, L.; Khataee, A.; Reyhanitabar, A.; Oustan, S. Reductive removal of $\mathrm{Cr}(\mathrm{VI})$ by starch-stabilized $\mathrm{Fe}^{0}$ nanoparticles in aqueous solution. Desalination 2011, 270, 105-110.

Baig, S. A.; Zhu, J.; Muhammad, N.; Sheng, T.; Xu, X. Effect of synthesis methods on magnetic Kans grass biochar for enhanced As (III, V) adsorption from aqueous solutions. Biomass Bioenergy 2014, 71, 299-310.

Bhatti, H. N.; Hayat, J.; Iqbal, M.; Noreen, S.; Nawaz, S. Biocomposite application for the phosphate ions removal in aqueous medium. J. Mater. Res. Technol. 2018, 7, 300-307.

Boparai, H. K.; Joseph, M.; O'Carroll, D. M. Kinetics and thermodynamics of cadmium ion removal by adsorption onto nano zerovalent iron particles. J. Hazard. Mater. 2011, 186, 458-465.

Boparai, H. K.; Joseph, M.; O’Carroll, D. M. Cadmium $\left(\mathrm{Cd}^{2+}\right)$ removal by nano zerovalent iron: surface analysis, effects of solution chemistry and surface complexation modeling. Environ. Sci. Pollut. Res. 2013, 20, 6210-6221.

Box, G. E.; Behnken, D. W. Some new three level designs for the study of quantitative variables. Technometrics 1960, 2, 455-475.

Chen, X.; Chen, G.; Chen, L.; Chen, Y.; Lehmann, J.; McBride, M. B.; Hay, A. G. Adsorption of copper and zinc by biochars produced from pyrolysis of hardwood and corn straw in aqueous solution. Bioresour. Technol. 2011, 102, 8877-8884.

Chowdhury, S.; Saha, P. D. Batch and continuous (fixed-bed column) biosorption of $\mathrm{Cu}$ (II) by Tamarindus indica fruit shell. Korean J. Chem. Eng. 2013, 30, 369-378.

Cui, X.; Hao, H.; Zhang, C.; He, Z.; Yang, X. Capacity and mechanisms of ammonium and cadmium sorption on different wetland-plant derived biochars. Sci. Total Environ. 2016, 539, 566-575.

Demirbas, A. Heavy metal adsorption onto agro-based waste materials: a review. J. Hazard. Mater. 2008, 157, 220-229.

Devi, P.; Saroha, A. K. Simultaneous adsorption and dechlorination of pentachlorophenol from effluent by $\mathrm{Ni}-\mathrm{ZVI}$ magnetic biochar composites synthesized from paper mill sludge. Chem. Eng. J. 2015, 271, 195-203.

Doumer, M.; Rigol, A.; Vidal, M.; Mangrich, A. Removal of Cd, Cu, Pb, and $\mathrm{Zn}$ from aqueous solutions by biochars. Environ. Sci. Pollut. Res. 2016, 23, 2684-2692.

EBC. European Biochar Certificate - guidelines for a sustainable production of biochar. 2012, Internet. http://www.europeanbiochar.org/biochar/media/doc/1358641517626.pdf.

Esfahani, A. R.; Firouzi, A. F.; Sayyad, G.; Kiasat, A.; Alidokht, L.; Khataee, $\mathrm{A}$. $\mathrm{Pb}$ (II) removal from aqueous solution by polyacrylic acid stabilized zero-valent iron nanoparticles: process optimization using response surface methodology. Res. Chem. Intermed. 2014, 40, 431-445.

Ferreira, S. C.; Bruns, R.; Ferreira, H.; Matos, G.; David, J.; Brandao, G.; da Silva, E. P.; Portugal, L.; Dos Reis, P.; Souza, 
A. Box-Behnken design: an alternative for the optimization of analytical methods. Anal. Chim. Acta 2007, 597, 179-186.

Fu, F.; Wang, Q. Removal of heavy metal ions from wastewaters: a review. J. Environ. Manage. 2011, 92, 407-418.

Gan, C.; Liu, Y.; Tan, X.; Wang, S.; Zeng, G.; Zheng, B.; Li, T.; Jiang, Z.; Liu, W. Effect of porous zinc-biochar nanocomposites on $\mathrm{Cr}$ (vi) adsorption from aqueous solution. RSC Adv. 2015, 5, 35107-35115.

Ghorbani, F.; Younesi, H.; Mehraban, Z.; Celik, M. S.; Ghoreyshi, A.; Anbia, M. Aqueous cadmium ions removal by adsorption on APTMS grafted mesoporous silica MCM-41 in batch and fixed bed column processes. Int. J. Eng. 2013, 26, 473-488.

Göksungur, Y.; Üren, S.; Güvenç, U. Biosorption of cadmium and lead ions by ethanol treated waste baker's yeast biomass. Bioresour. Technol. 2005, 96, 103-109.

Han, L.; Xue, S.; Zhao, S.; Yan, J.; Qian, L.; Chen, M. Biochar supported nanoscale iron particles for the efficient removal of methyl orange dye in aqueous solutions. PLoS One 2015, 10, e0132067.

Huang, P.; Ye, Z.; Xie, W.; Chen, Q.; Li, J.; Xu, Z.; Yao, M. Rapid magnetic removal of aqueous heavy metals and their relevant mechanisms using nanoscale zero valent iron (nZVI) particles. Water Res. 2013, 47, 4050-4058.

Jiang, Z.; Lv, L.; Zhang, W.; Du, Q.; Pan, B.; Yang, L.; Zhang, Q. Nitrate reduction using nanosized zero-valent iron supported by polystyrene resins: role of surface functional groups. Water Res. 2011, 45, 2191-2198.

Kastner, J. R.; Mani, S.; Juneja, A. Catalytic decomposition of tar using iron supported biochar. Fuel Process. Technol. 2015, 130, 31-37.

Kloss, S.; Zehetner, F.; Dellantonio, A.; Hamid, R.; Ottner, F.; Liedtke, V.; Schwanninger, M.; Gerzabek, M. H.; Soja, G. Characterization of slow pyrolysis biochars: effects of feedstocks and pyrolysis temperature on biochar properties. J. Environ. Qual. 2012, 41, 990-1000.

Li, X. Q.; Zhang, W. X. Iron nanoparticles: The core-shell structure and unique properties for $\mathrm{Ni}$ (II) sequestration. Langmuir 2006, $22,4638-4642$.

Li, X. Q.; Zhang, W. X. Sequestration of metal cations with zerovalent iron nanoparticles a study with high resolution X-ray photoelectron spectroscopy (HR-XPS). J. Phys. Chem. C 2007, 111, 6939-6946.

Li, Y. H.; Wang, S.; Luan, Z.; Ding, J.; Xu, C.; Wu, D. Adsorption of cadmium (II) from aqueous solution by surface oxidized carbon nanotubes. Carbon 2003, 41, 1057-1062.

Mukherjee, A.; Zimmerman, A.; Harris, W. Surface chemistry variations among a series of laboratory-produced biochars. Geoderma 2011, 163, 247-255.

Myers, R.; Montgomery, D. Response Surface Methodology: Process and Product Improvement with Designed Experiments. John Wiley \& Sons, New York, 2002.

Ngah, W. W.; Hanafiah, M. Removal of heavy metal ions from wastewater by chemically modified plant wastes as adsorbents: a review. Bioresour. Technol. 2008, 99, 3935-3948.

Park, D.; Lim, S. R.; Yun, Y. S.; Park, J. M. Development of a new $\mathrm{Cr}$ (VI)-biosorbent from agricultural biowaste. Bioresour. Technol. 2008, 99, 8810-8818.

Peng, X.; Liu, X.; Zhou, Y.; Peng, B.; Tang, L.; Luo, L.; Yao, B.; Deng, Y.; Tang, J.; Zeng, G. New insights into the activity of a biochar supported nanoscale zerovalent iron composite and nanoscale zero valent iron under anaerobic or aerobic conditions. RSC Adv. 2017, 7, 8755-8761.
Phenrat, T.; Saleh, N.; Sirk, K.; Kim, H. J.; Tilton, R. D.; Lowry, G. V. Stabilization of aqueous nanoscale zerovalent iron dispersions by anionic polyelectrolytes: adsorbed anionic polyelectrolyte layer properties and their effect on aggregation and sedimentation. J. Nanopart. Res. 2008, 10, 795-814.

Pi, L.; Jiang, R.; Zhou, W.; Zhu, H.; Xiao, W.; Wang, D.; Mao, X. G-C3N4 modified biochar as an adsorptive and photocatalytic material for decontamination of aqueous organic pollutants. Appl. Surf. Sci. 2015, 358, 231-239.

Qambrani, N. A.; Rahman, M. M.; Won, S.; Shim, S.; Ra, C. Biochar properties and eco-friendly applications for climate change mitigation, waste management, and wastewater treatment: a review. Renewable Sustainable Energy Rev. 2017, $79,255-273$.

Quan, G.; Sun, W.; Yan, J.; Lan, Y. Nanoscale zero-valent iron supported on biochar: characterization and reactivity for degradation of acid orange 7 from aqueous solution. Water Air Soil Pollut. 2014a, 225, 2195.

Quan, G.; Zhang, J.; Guo, J.; Lan, Y. Removal of $\mathrm{Cr}$ (VI) from aqueous solution by nanoscale zero-valent iron grafted on acid-activated attapulgite. Water Air Soil Pollut. 2014b, 225, 1979.

Rahmani, A.; Ghaffari, H.; Samadi, M. A comparative study on arsenic (III) removal from aqueous solution using nano and micro sized zero-valent iron. Iranian J. Environ. Health Sci. Eng. 2011, $8,175$.

Rao, K.; Mohapatra, M.; Anand, S.; Venkateswarlu, P. Review on cadmium removal from aqueous solutions. Int. J. Eng. Sci. Technol. 2010, 2, 81-103.

Rao, K. S.; Anand, S.; Rout, K.; Venkateswarlu, P. Response surface optimization for removal of cadmium from aqueous solution by waste agricultural biosorbent Psidium guvajava L. leaf powder. Clean Soil Air Water 2012, 40, 80-86.

Salmani, M.; Ehrampoush, M.; Sheikhalishahi, S.; Dehvari, M. Removing copper from contaminated water using activated carbon sorbent by continuous flow. J. Community Health Res. 2012, 1, 11-18.

Satarug, S.; Garrett, S. H.; Sens, M. A.; Sens, D. A. Cadmium, environmental exposure, and health outcomes. Cienc. Saude Coletiva 2011, 16, 2587-2602.

Savasari, M.; Emadi, M.; Bahmanyar, M. A.; Biparva, P. Optimization of Cd (II) removal from aqueous solution by ascorbic acidstabilized zero valent iron nanoparticles using response surface methodology. J. Ind. Eng. Chem. 2015, 21, 1403-1409.

Sharma, Y. Thermodynamics of removal of cadmium by adsorption on an indigenous clay. Chem. Eng. J. 2008, 145, 64-68.

Sharma, R. K.; Wooten, J. B.; Baliga, V. L.; Lin, X.; Chan, W. G.; Hajaligol, M. R. Characterization of chars from pyrolysis of lignin. Fuel 2004, 83, 1469-1482.

Shi, Z.; Nurmi, J. T.; Tratnyek, P. G. Effects of nano zero-valent iron on oxidation-reduction potential. Environ. Sci. Technol. 2011, 45, 1586-1592.

Singh, B.; Singh, B. P.; Cowie, A. L. Characterisation and evaluation of biochars for their application as a soil amendment. Soil Res. 2010, 48, 516-525.

Sohi, S. P. Carbon storage with benefits. Science 2012, 338, 1034-1035.

Song, Z.; Lian, F.; Yu, Z.; Zhu, L.; Xing, B.; Qiu, W. Synthesis and characterization of a novel $\mathrm{MnOx}$-loaded biochar and its adsorption properties for $\mathrm{Cu}^{2+}$ in aqueous solution. Chem. Eng. J. 2014, 242, 36-42. 
Sun, J.; Lian, F.; Liu, Z.; Zhu, L.; Song, Z. Biochars derived from various crop straws: characterization and Cd (II) removal potential. Ecotoxicol. Environ. Saf. 2014, 106, 226-231.

Tan, X.; Liu, Y.; Zeng, G.; Wang, X.; Hu, X.; Gu, Y.; Yang, Z. Application of biochar for the removal of pollutants from aqueous solutions. Chemosphere 2015, 125, 70-85.

Tan, X. F.; Liu, Y. G.; Gu, Y. L.; Xu, Y.; Zeng, G. M.; Hu, X. J.; Liu, S. B.; Wang, X.; Liu, S. M.; Li, J. Biochar-based nano-composites for the decontamination of wastewater: a review. Bioresour. Technol. 2016, 212, 318-333.

Tchounwou, P. B.; Yedjou, C. G.; Patlolla, A. K.; Sutton, D. J. Heavy metal toxicity and the environment. In Molecular, Clinical and Environmental Toxicology, Springer, Basel, 2012; pp 133-164.

Usman, A.; Sallam, A.; Zhang, M.; Vithanage, M.; Ahmad, M.; Al-Farraj, A.; Ok, Y. S.; Abduljabbar, A.; Al-Wabel, M. Sorption process of date palm biochar for aqueous Cd (II) removal: Efficiency and mechanisms. Water Air Soil Pollut. 2016, 227, 449.

Wang, F. Y.; Wang, H.; Ma, J. W. Adsorption of cadmium (II) ions from aqueous solution by a new low-cost adsorbent - bamboo charcoal. J. Hazard. Mater. 2010, 177, 300-306.

Wang, D.; Zhang, W.; Zhou, D. Antagonistic effects of humic acid and iron oxyhydroxide grain-coating on biochar nanoparticle transport in saturated sand. Environ. Sci. Technol. 2013, 47, 5154-5161.

Wang, H.; Gao, B.; Wang, S.; Fang, J.; Xue, Y.; Yang, K. Removal of Pb (II), CU (II), and Cd (II) from aqueous solutions by biochar derived from $\mathrm{KMnO}_{4}$ treated hickory wood. Bioresour. Technol. 2015a, 197, 356-362.
Wang, S.; Gao, B.; Zimmerman, A. R.; Li, Y.; Ma, L.; Harris, W. G.; Migliaccio, K. W. Removal of arsenic by magnetic biochar prepared from pinewood and natural hematite. Bioresour. Technol. 2015b, 175, 391-395.

Yan, J.; Han, L.; Gao, W.; Xue, S.; Chen, M. Biochar supported nanoscale zerovalent iron composite used as persulfate activator for removing trichloroethylene. Bioresour. Technol. 2015, 175, 269-274.

Yang, J.; Zhao, Y.; Ma, S.; Zhu, B.; Zhang, J.; Zheng, C. Mercury removal by magnetic biochar derived from simultaneous activation and magnetization of sawdust. Environ. Sci. Technol. 2016, 50, 12040-12047.

Yao, Y.; Gao, B.; Chen, J.; Zhang, M.; Inyang, M.; Li, Y.; Yang, L. Engineered carbon (biochar) prepared by direct pyrolysis of $\mathrm{Mg}$ accumulated tomato tissues: characterization and phosphate removal potential. Bioresour. Technol. 2013, 138, 8-13.

Zhang, M.; Gao, B.; Yao, Y.; Xue, Y.; Inyang, M. Synthesis of porous MgO-biochar nanocomposites for removal of phosphate and nitrate from aqueous solutions. Chem. Eng. J. 2012, 210, 26-32.

Zhang, M.; Gao, B.; Varnoosfaderani, S.; Hebard, A.; Yao, Y.; Inyang, $M$. Preparation and characterization of a novel magnetic biochar for arsenic removal. Bioresour. Technol. 2013, 130, 457-462.

Zhu, S.; Ho, S.-H.; Huang, X.; Wang, D.; Yang, F.; Wang, L.; Wang, C.; Cao, X.; Ma, F. Magnetic nanoscale zero valent iron assisted biochar: interfacial chemical behaviors and heavy metals remediation performance. ACS Sustain. Chem. Eng. 2017, 5, 9673-9682. 